\title{
Comprehensive calculation of the energy per ion pair or $W$ values for five major planetary upper atmospheres
}

\author{
C. Simon Wedlund ${ }^{1}$, G. Gronoff ${ }^{2}$, J. Lilensten ${ }^{3}$, H. Ménager $^{3}$, and M. Barthélemy ${ }^{3}$ \\ ${ }^{1}$ Belgian Institute for Space Aeronomy, BIRA-IASB, Brussels, Belgium \\ ${ }^{2}$ NASA Langley Research Center, Hampton, VA, USA \\ ${ }^{3}$ Institut de Planétologie et d'Astrophysique de Grenoble, IPAG, Grenoble, France
}

Received: 8 September 2010 - Revised: 31 December 2010 - Accepted: 13 January 2011 - Published: 24 January 2011

\begin{abstract}
The mean energy $W$ expended in a collision of electrons with atmospheric gases is a useful parameter for fast aeronomy computations. Computing this parameter in transport kinetic models with experimental values can tell us more about the number of processes that have to be taken into account and the uncertainties of the models. We present here computations for several atmospheric gases of planetological interest $\left(\mathrm{CO}_{2}, \mathrm{CO}, \mathrm{N}_{2}, \mathrm{O}_{2}, \mathrm{O}, \mathrm{CH}_{4}, \mathrm{H}, \mathrm{He}\right)$ using a family of multi-stream kinetic transport codes. Results for complete atmospheres for Venus, Earth, Mars, Jupiter and Titan are also shown for the first time. A simple method is derived to calculate $W$ of gas mixtures from single-component gases and is conclusively checked against the $W$ values of these planetary atmospheres. Discrepancies between experimental and theoretical values show where improvements can be made in the measurement of excitation and dissociation cross-sections of specific neutral species, such as $\mathrm{CO}_{2}$ and $\mathrm{CO}$.
\end{abstract}

Keywords. Ionosphere (Planetary ionospheres) - Space plasma physics (Ionization processes; Transport processes)

\section{Introduction}

The mean energy expended by an electron in colliding with an atmospheric molecule is a useful metric in determining overall ionization efficiency of a gas or gas mixture. Following a method proposed by Chamberlain (1961), the ion and electron production height profiles can be calculated to derive the emission lines without having to solve a kinetic transport equation. Even though computers today are much more powerful than before, multi-stream transport codes are sparse in a planetology context. Therefore, many recent works still use the Chamberlain method (e.g., Semeter and Kalamabadi,

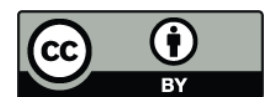

Correspondence to: C. Simon Wedlund (cyril.simon@aeronomie.be)
2005). This parameter, noted $W$, is sometimes called " $W$ value" (Samson and Haddad, 1975), "energy loss per ion pair" (Kozelov and Ivanov, 1994) or, simply, "mean energy per ion pair" (Edgar et al., 1973). Its variation with the energy of an incident electron depends on the interplay between ionization, excitation and heating processes. $W$ is expressed as:

$W=E_{i} /<N>[\mathrm{eV}]$

Where $E_{i}$ is the energy of the incident electron and $\langle N\rangle$ the average number of electron-ion pairs produced. An equivalent way to write it is:

$W_{\text {full }}=Q_{\text {full }} / P_{i}$

Where $Q_{\text {full }}$ is the total energy input flux in $\mathrm{eV} \mathrm{cm}^{-2} \mathrm{~s}^{-1}$ that will be absorbed through ionisation, excitation and heating and $P_{i}$ is the total column ion production rate $\left(\mathrm{cm}^{-2} \mathrm{~s}^{-1}\right)$.

\subsection{Previous studies}

Some of the first experimental works quantified $W$ for $\mathrm{He}$, Ar, $\mathrm{H}_{2}, \mathrm{CO}_{2}$ and $\mathrm{N}_{2}$ (Lehmann and Osgood, 1927). Bagge (1937) and then Fano (1946) derived approximate theoretical formulas for $W$ as a ratio of cross sections showing that, while $W$ had different values for different gases, it was of the order of $30 \mathrm{eV}$ and was nearly independent of the ionising radiation. Measurements on molecular hydrogen confirmed that this ratio is approximately constant around $1 \mathrm{keV}$ and equalled 35 to $37 \mathrm{eV}$ (e.g., Dalgarno and Griffing, 1958, and references therein).

Theoretical interpretations such as Bethe's (1930) and Dalgarno and Griffing's (1958) produced the first consistent model of the degradation of an electron/proton beam in atomic hydrogen using the Bethe-Born formalism ( $W$ was found constant at $36 \mathrm{eV} /$ pair above $1 \mathrm{keV}$ ).

Jesse and Sadaukis (1957) measured the impact of $\alpha$ and $\beta$ particles from ${ }^{35} \mathrm{~S}$ in an ionisation chamber filled with gases

Published by Copernicus Publications on behalf of the European Geosciences Union. 
Table 1. Energy per ion pair for planets and gases. $\mathrm{SI}=$ Sergienko and Ivanov (1993) for $\mathrm{N}_{2}, \mathrm{O}_{2}$ and O. DYL=Dalgarno et al. (1999) for H, $\mathrm{H}_{2}$ and $\mathrm{He}$. LV = Liu and Victor (1994) for CO. The uncertainties for $W(\mathrm{He})$ reach $10 \%$ at $2 \mathrm{keV}$ input energy, this is due to a combination of energy conservation in the solving scheme as well as on the cross sections. $W($ Jupiter $)$ and $W(\mathrm{H})$ have uncertainties of the order of $5 \%$. $W\left(\mathrm{O}_{2}\right)$ has an uncertainty of $6 \%$, which affects in turn $W$ (Earth), $W$ (Mars) and $W$ (Venus). $\mathrm{N}_{2}, \mathrm{O}, \mathrm{CO}_{2}$ and $\mathrm{CO} W$ values have uncertainties of $8 \%, 5 \%, 13 \%$ and $15 \%$ when taking cross sections uncertainties and energy conservation into account. Experimental values are taken from ICRU Report 31 (1993) for electrons and from Jesse and Sadaukis (1957) for $\beta$ and $\alpha$ particles as the ionisation source, given here for comparison (uncertainties claimed to be $1.5 \%$ ). Note that $W(\mathrm{He}), W\left(\mathrm{H}_{2}\right)$ and $W(\mathrm{H})$ uncertainties, highlighted by the symbol ${ }^{\circ}$, are only due to the numerical scheme (energy conservation) and are a lower estimate.

\begin{tabular}{|c|c|c|c|c|c|c|}
\hline \multirow[b]{2}{*}{$\begin{array}{l}\text { Atmosphere } \\
\text { or gas }\end{array}$} & \multicolumn{6}{|c|}{ Average $W$ value (in eV) } \\
\hline & $\begin{array}{l}\text { Green et al. } \\
\quad(1977)\end{array}$ & $\begin{array}{c}\mathrm{SI}^{*} \\
\mathrm{DYL}^{\dagger}, \mathrm{LV}^{\dagger}\end{array}$ & $\begin{array}{l}\text { Fox et al. } \\
(2008)\end{array}$ & $\begin{array}{l}\text { Jesse and Sadaukis (1957) } \\
\qquad \beta-\alpha\end{array}$ & $\begin{array}{l}\text { Experimental values } \\
\text { (ICRU Report 31, 1993) }\end{array}$ & $\begin{array}{l}\text { This study } \\
E_{i}=2 \mathrm{keV}\end{array}$ \\
\hline Mars & & & & & & $28.4 \pm 4.3$ \\
\hline Venus & & & & & & $28.7 \pm 4.3$ \\
\hline Earth & 32.3 & & & & & $31.7 \pm 1.7$ \\
\hline Titan & & & & & & $34.1 \pm 1.5$ \\
\hline Jupiter & & & & & & $36.2 \pm 1.8$ \\
\hline $\mathrm{N}_{2}$ & 35.3 & $36.8^{*}$ & 37 & $35.0 \beta-36.6 \alpha$ & $34.8 \pm 0.2$ & $34.3 \pm 1.8$ \\
\hline $\mathrm{O}_{2}$ & 30.9 & $28.2^{*}$ & 31 & $30.9 \beta-32.5 \alpha$ & $30.8 \pm 0.4$ & $27.8 \pm 1.7$ \\
\hline $\mathrm{O}$ & 27.4 & $26.8^{*}$ & & - & - & $26.4 \pm 1.5$ \\
\hline $\mathrm{CO}_{2}$ & 32.5 & & 34 & $32.9 \beta-34.5 \alpha$ & $33.0 \pm 0.7$ & $28.0 \pm 3.8$ \\
\hline $\mathrm{CO}$ & 33.5 & $32.3^{\ddagger}$ & 34 & - & - & $29.4 \pm 4.7$ \\
\hline $\mathrm{CH}_{4}$ & & & 31 & $27.3 \beta-29.2 \alpha$ & $27.3 \pm 0.3$ & $28.0 \pm 1.2$ \\
\hline $\mathrm{H}$ & & $36.1^{\dagger}$ & & - & - & $37.8 \pm 1.8^{\circ}$ \\
\hline $\mathrm{H}_{2}$ & 36.3 & $37.7^{\dagger}$ & 36 & $36.3 \beta-36.3 \alpha$ & $36.5 \pm 0.3$ & $36.2 \pm 0.7^{\circ}$ \\
\hline $\mathrm{He}$ & 46.3 & $46.3^{\dagger}$ & 44 & $42.3 \beta-42.7 \alpha$ & $41.3 \pm 1.0$ & $46.3 \pm 4.6^{\circ}$ \\
\hline
\end{tabular}

of $\mathrm{N}_{2}, \mathrm{O}_{2}, \mathrm{CO}_{2}, \mathrm{CH}_{4}, \mathrm{H}_{2}$ and $\mathrm{He}$, reporting uncertainties of the order of $1.5 \%$. These data are summarised in Table 1 and show a significant variation depending on the nature of the impacting particle except for rare gases and $\mathrm{H}_{2}$.

Valentine and Curran (1958) derived formulas using partial pressures to calculate $W$ for a mixture of gases knowing the value for each gas while Platzman (1961) stressed three ways to calculate $W$ (from cross sections, from energy balance and from the degradation spectrum).

As an application to Earth's ionosphere, Chamberlain (1961) and then Rees (1963) proposed a formula to retrieve the total ionisation rate for mono-energetic electron beams of energy $E_{p}$ :

$q\left(z, E_{p}\right)=\eta\left(z, E_{p}\right) / W_{\text {full }}\left[\mathrm{cm}^{-3} \mathrm{~s}^{-1}\right]$

where $\eta\left(z, E_{p}\right)$ is the energy deposition rate in $\mathrm{eV} \mathrm{cm}^{-3} \mathrm{~s}^{-1}$ to be computed using the energy dissipation function (as formulated, for example, in Sergienko and Ivanov, 1993). $W_{\text {full }}$ is usually taken to be constant equal to $35 \mathrm{eV}$ (Rees, 1989). This approach enabled the fast computation of the energy deposition in Earth's atmosphere without using a more timeconsuming transport code.

By using new data sets for the study of auroral and dayglow intensities, Stolarski and Green (1967) took into account electron energies less than $30 \mathrm{keV}$ in a mixture of gases made of $45 \%$ of $\mathrm{N}_{2}, 45 \%$ of $\mathrm{O}_{2}$ and $10 \%$ of $\mathrm{O}$ representative of thermospheric altitudes. They calculated a $W$ value of $32.3 \mathrm{eV}$ at $1 \mathrm{keV}$.

Edgar et al. (1973) reconsidered the problem for proton precipitation at Earth. They produced a complete curve of the $W$ values for protons of energies ranging from $100 \mathrm{eV}$ to $10 \mathrm{MeV}$. In pure nitrogen $\mathrm{N}_{2}$, this approach resulted in an energy per ion pair equal to $38 \mathrm{eV}$ at $100 \mathrm{keV}$ and $35 \mathrm{eV}$ at $1 \mathrm{MeV}$. Two regimes were identified with charge exchange reactions being efficient up to $100 \mathrm{keV}$ while primary protoionisation and secondary electron production take over for higher incident proton energies. The value at high energies was close to the value found for an electron beam or for alpha particles.

What is the influence of inner K-shell ionisation on the energy loss per ion pair? Khare and Kumar (1977, 1978) published two studies on the subject using Fowler's theoretical method (see Inokuti, 1975). $W$ values in $\mathrm{N}_{2}$ and $\mathrm{O}_{2}$ were found to be $36.9 \mathrm{eV}$ at $1 \mathrm{keV}$ and $30.7 \mathrm{eV}$ at $500 \mathrm{eV}$, respectively, both within the span of experimental values. It is to be noted that the inclusion of Auger electron ionisation decreased the originally much too large $W$ values calculated by Khare $(1970,1971)$ by up to $6 \%$ allowing his final results to be close to experimental values (see Avakyan and Kudryashev, 1988, for a critical account of the current methods to calculate the energy per ion pair and the inclusion of Auger processes). 
Theoretical studies were carried out in different gases by Green et al. (1977) using a discrete-energy-bin algorithm to calculate the yield spectra for nine gases including argon. Their results at $1 \mathrm{keV}$ incident energy are summarised in Table 1.

As computing power increased, kinetic transport methods became more common. Pioneering studies included Bretagne et al. (1981) and Strickland and Ali (1982). Slinker et al. $(1988,1990)$ solved a kinetic transport equation to describe the discrete entry of high energy electrons in atomic oxygen $\mathrm{O}$ and nitrogen $\mathrm{N}_{2}$ and found $W$ to be $27.9 \mathrm{eV}$ and $38.8 \mathrm{eV}$ at $1 \mathrm{keV}$.

Sergienko and Ivanov (1993) computed the energy per ion pair in a multi-constituent Earth atmosphere for auroral electrons with a Monte Carlo code. Their parametrisation of the energy lost in the ion and excitation states, called the "excitation energy cost", allowed to derive production profiles of excited and ionized states of $\mathrm{N}_{2}, \mathrm{O}_{2}$ and $\mathrm{O}$ without solving the Boltzmann transport equation. The energy losses per ion pair for $\mathrm{N}_{2}, \mathrm{O}_{2}$ and $\mathrm{O}$ were found to be $36.8 \mathrm{eV}, 28.2 \mathrm{eV}$ and $26.8 \mathrm{eV}$ at $1 \mathrm{keV}$ input energy (Table 1 ).

Kozelov and Ivanov (1994) extended this previous work to proton precipitation. Adopting the remark of Basu et al. (1993), they noted that the total energy deposited in the atmosphere was not the same as the incident energy of the beam because of the backscattered flux. They found an asymptotic value of $35 \mathrm{eV}$ at $E_{i} \leq 1 \mathrm{keV}$ in a $\left(\mathrm{N}_{2}, \mathrm{O}_{2}, \mathrm{O}\right)$ atmosphere.

Strickland et al. (1993) developed a kinetic electronproton transport model to yield the energy deposition in an atmosphere given by the thermospheric model MSIS (Hedin, 1991). Electrons and protons behaved differently: the $W$ value for electrons was rather constant at around $34 \mathrm{eV}$ from $100 \mathrm{eV}$ to $100 \mathrm{keV}$ when taking into account the backscattered flux, while the variation for a pure proton beam was much more important (26 to $30 \mathrm{eV}$ from $1 \mathrm{keV}$ to $20 \mathrm{keV}$ protons).

\subsection{Motivation}

In spite of the different values cited above, the mean value of $35 \mathrm{eV} /$ pair is currently adopted in the aeronomy community (Rees, 1989). Not only is it used for Earth modelling but, as planetology progresses, it is also used for the study of planetary atmospheres. In the present paper, we wish to reconsider this value for Earth, Mars, Venus, Jupiter and Titan using a kinetic transport code based on Boltzmann's formalism and atmosphere models representing realistic atmospheres.

Following the conclusions of the ICRU report 31 (1993), the consistent modelling of $W$ values must take into account two ingredients: first, the accurate determination of all electron collision inelastic cross sections including excitation, molecular dissociation, total ionisation and differential ionisation (secondary electron); second, the bookkeeping, i.e., the assessment of the overall cumulative influence of each inelastic cross section. Thus, the differences between the results of a model and experimental values tells us about the comprehensiveness and the reliability of the cross section data sets used in models. These ingredients are crucial for a quantitative understanding of planetary upper atmospheres as a whole in order to prepare for new exploration missions. $W$ values can then be used as a means of testing the accuracy and completeness of our cross section databases.

\section{Description of the model and uncertainties}

Basu et al. (1993) already mentioned that the value may be different when considering backscattering or not. This is not a simple statement. In both cases of electron and proton precipitation, a non-negligible fraction of the ions/electrons are sent back to the magnetosphere (Lilensten et al., 1990). In the case of cosmic rays for example, the main ionization occurs so low in the atmospheres that there is hardly any energy backscattered. However, the value of $35 \mathrm{eV}$ is also used in this case. This is why it is necessary to consider the two values $Q_{\text {full }}$ and $Q_{\text {BS. }} Q_{\text {full }}$, the "full ionization cost", is considered when there is no backscattering. $Q_{\text {net }}$, the "net ionization cost", takes backscattering $Q_{\mathrm{BS}}$ into account so that:

$Q_{\text {net }}=Q_{\text {full }}-Q_{\text {BS }}\left[\mathrm{eV} \mathrm{cm}^{-2} \mathrm{~s}^{-1}\right]$

While $W_{\text {full }}$ is directly linked to experimental measurements, $W_{\text {net }}$ is the relevant quantity in a numerical model where energy conservation is of crucial importance.

We use the TRANS-* family of codes adapted to Earth (Simon et al., 2007), Venus (Gronoff et al., 2007, 2008), Mars (Simon et al., 2009), Titan (Lilensten et al., 2005; Gronoff et al., 2009) and Jupiter (Ménager et al., 2010) as discussed below. The TRANS-* codes solve the 1-D kinetic transport Boltzmann equation for suprathermal electrons including updated elastic, ionisation, excitation and dissociative cross sections. Cross sections and their corresponding uncertainties are reported and detailed in the recent review works of Johnson et al. (2005) for O, Itikawa (2002, 2006, 2009) for $\mathrm{CO}_{2}, \mathrm{~N}_{2}$ and $\mathrm{O}_{2}$ and Avakyan (1998) for all other species.

In this study, the main inputs are electron precipitation spectra and neutral atmospheres. Each neutral atmosphere model is used for night conditions with a solar zenith angle superior to $108^{\circ}$. Middle latitudes of $50^{\circ}$ are used whenever possible, and solar activity is taken to be low $\left(f_{10.7}=\right.$ 100). For Earth's thermosphere, we use the model MSIS90 (Hedin, 1991) with $\mathrm{N}_{2}, \mathrm{O}_{2}, \mathrm{O}$ as main three components. For Venus we use VTS3 (Hedin et al., 1983) with $\mathrm{CO}_{2}, \mathrm{~N}_{2}$, $\mathrm{CO}, \mathrm{O}, \mathrm{H}$ and $\mathrm{N} . \mathrm{O}_{2}$ is manually included with $\left[\mathrm{O}_{2}\right]=10^{-3}$ $\left[\mathrm{CO}_{2}\right]$ as in Gronoff et al. (2007). For Mars, we use MTGCM (Bougher et al., 1999) with $\mathrm{CO}_{2}, \mathrm{CO}, \mathrm{N}_{2}, \mathrm{O}_{2}$ and $\mathrm{O}$ applied to the Viking/Mariner conditions (e.g., Simon et al., 2009). For Titan, we use the model of Müller-Wodarg et al. (2000) and Cui et al. (2009) with $\mathrm{N}_{2}$ and $\mathrm{CH}_{4}$. For Jupiter, we use 
the auroral model of Grodent and Gérard (2001) with $\mathrm{H}, \mathrm{H}_{2}$, $\mathrm{He}$ and $\mathrm{CH}_{4}$.

The source of the electrons is set in the planetary exospheres $(800 \mathrm{~km}$ altitude for Earth, $500 \mathrm{~km}$ for Mars and Venus, $1000 \mathrm{~km}$ for Titan, $1850 \mathrm{~km}$ for Jupiter). We tested several shapes of electron precipitation (Dirac, Gaussian, Maxwellian) with characteristic energies varying from the ionisation threshold up to $10^{4} \mathrm{eV}$. The two first distributions yield similar results while Maxwellian distributions are too extended in energy to be safely interpreted within the frame of this study. The integrated energy flux is $1 \mathrm{erg} \mathrm{cm}^{-2} \mathrm{~s}^{-1}$ for all planets, even though this parameter has no influence on the ionisation cost.

Since we are computing the energy per electron-ion pair, the numerical uncertainty on $W$ is given by the energy conservation of the numerical model as well as the intrinsic cross section uncertainties. Uncertainties propagate in numerical models and are very seldom taken into account. For instance, following Cassini measurements of Titan's atmosphere, a whole domain of planetary chemistry is rapidly emerging which aims at evaluating the effects of chemical parameter uncertainties (such as reaction rates) on the models (see for example Carrasco et al., 2007). It is therefore of prime importance to evaluate the uncertainty on $W$ and assess this error propagation in future planetary models.

- For an ideal energy conservation of $100 \%$, the total absorbed flux equals the input flux minus the backscattered one. For Earth, Mars, Venus and Titan, we performed hundreds of runs varying the resolution of the energy grid to reach an energy conservation better than $98 \%$. For Jupiter, an energy conservation of $95 \%$ on average was reached. When computing $W$ values in single-constituent atmospheres, the uncertainties on cross sections must also be carefully checked. For $\mathrm{O}_{2}$, it is very difficult to estimate cross sections for energies above $1 \mathrm{keV}$ : extrapolation schemes suffer from uncertainties, which in the case of $\mathrm{O}_{2}$ can amount to a few percent at $2 \mathrm{keV}$ input energy on top of the intrinsic cross section uncertainties.

- The comprehensive inclusion of molecular and atomic excitation cross sections (bookkeeping) is crucial as it can account for a large part of the absorbed input energy. To calculate the accurate statistical propagation of cross section uncertainties in our model and the effect on $W$ values, a Monte Carlo approach is used by assuming that the claimed cross section uncertainties follow a normal law (see Bevington and Robinson, 2003). By fitting a Gaussian on the resulting distribution, a $1 \sigma$ error can be defined which is a good estimate of cross section uncertainties on $W$ values. These uncertainties are summarised in Table 1. To propagate the cross section uncertainty, we assume that the claimed uncertainty in the sources (mainly measurements) are equal to the standard deviation (e.g. 1- $\sigma$ ) of the normal law.
To account for differential cross sections, the approach of Lummerzheim and Lilensten (1994) based on the measurements of Opal et al. (1971) for $\mathrm{N}_{2}, \mathrm{O}_{2}$ and $\mathrm{O}$ was adopted for the other species. This particular cross section is then computed on the basis of the ionisation cross sections, which ensures a good conservation of the secondary electron energy distribution. The propagated uncertainty of this cross section on $W$ is too small compared to that of the total uncertainties on ionisation and excitation cross sections to have physical significance. Concerning the angular redistribution phase function, which is very important for the study of backscattered electrons, our sensitivity studies showed no influence on the $W$ parameter when varying the parameters of the phase function based on the work of Porter and Jump (1978) and Porter et al. (1987).

Auger processes (K-shell ionisation) can also be included in the model and a discussion is presented in the results section. Despite the lack of experimental and theoretical studies on K-shell electron impact cross sections for molecules (Avakyan, 1998) a rough estimate can however be deduced from the data of Frémont et al. (2006) and from Glupe and Mehlhorn (1967) for O. We used the ratio K-shell ionisation/total ionisation derived from these two studies to compute the corresponding K-shell cross sections. As no data are available for the ratio of $\mathrm{CO}_{2}$ and $\mathrm{CO}$, the ratio of $\mathrm{CH}_{4}$, which lies between the $\mathrm{C}$ and $\mathrm{O}$ ratios, is used as a first estimate. The estimation of these cross sections and their resulting effects are interesting from an observational point of view and will be discussed in more depth in a future work.

\section{Results and discussion}

\subsection{Planetary atmospheres}

Figure 1 shows the $W_{\text {net }}$ values computed by the model TRANS-* for several planets including Earth. Their behaviour is consistent with previous experimental and theoretical studies. From the ionisation threshold to about $100 \mathrm{eV}$ of input characteristic energy, the $W_{\text {net }}$ value decreases from more than $100 \mathrm{eV}$ per ion pair to reach a plateau at values depending on the planet. The values at $2 \mathrm{keV}$ input energy are summarised in Table 1 and vary from $28.4 \mathrm{eV}$ at Mars to $36.2 \mathrm{eV}$ at Jupiter. The $W$ value for Earth of $31.7 \mathrm{eV}$, derived from a mixed $\left(\mathrm{N}_{2}, \mathrm{O}_{2}, \mathrm{O}\right)$ atmosphere is smaller than the value usually accepted which is derived from a pure $\mathrm{N}_{2}$ atmosphere. Earth's value of $31.7 \pm 1.7 \mathrm{eV}$ is consistent with previous theoretical studies of the upper atmosphere (Green et al., 1977).

$W_{\text {full }}$ is usually higher than $W_{\text {net }}$ at low energies. This is due to the fact that at low energies, the energy deposition occurs at higher altitudes: the backscattered term is more important and energy escapes from the atmosphere, which is not taken into account in $W_{\text {full }}$. Above $100 \mathrm{eV}$ the electrons penetrate deeper in the atmosphere where backscattered fluxes are 


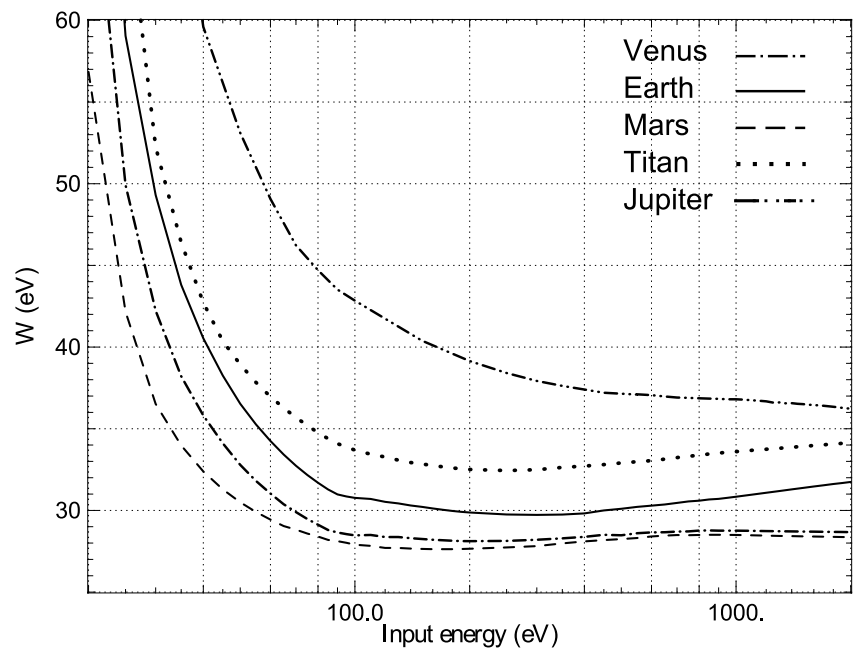

Fig. 1. Mean energy per electron-ion pair $W_{\text {net }}$ for Earth, Venus, Mars, Titan and Jupiter.

redistributed and take part directly in the energy deposition. Hence $W_{\text {full }}$ reaches the asymptotic value $W_{\text {net }}$ at energies above a few hundreds $\mathrm{eV}$ for all species.

Several phases are successively seen. The start-up phase is under $60 \mathrm{eV}$ where very few electron-ion pairs are created as excitation and heating are more efficient at these energies. At the ionisation threshold, $W$ becomes infinite. The recovery phase begins when ionisation processes become important with respect to excitation and more pairs are created: the curve decreases more slowly with increasing energies from $60 \mathrm{eV}$ up to $100 \mathrm{eV}$ typically. Finally, the equilibrium phase corresponds to the plateau observed between 400 and a few $\mathrm{keV}$ depending on the planet: the decrease of the cross sections is compensated by the increase in energy input. On Mars and Venus, a plateau is reached at $600 \mathrm{eV}$ up to higher energies: at the altitude of deposition of $2 \mathrm{keV}$ electrons (120 km altitude and downwards), the atmosphere composition and the relative proportion of main constituents do not change significantly any more. For Earth, $1-5 \mathrm{keV}$ electrons deposit their energy between 130 and $115 \mathrm{~km}$ altitude, where the thermosphere composition undergoes dramatic changes (competition between the three mains species $\mathrm{N}_{2}, \mathrm{O}_{2}$ and $\mathrm{O})$ : in this case a plateau is reached at higher energies than $5 \mathrm{keV}$. Above $5 \mathrm{keV}$, Auger processes must be taken into account. Auger electrons contribute to around 30\% of the total electron energy flux as shown in Avakyan (1983). However when calculating the energy degradation of Auger electrons we found that the modified $W$ value including Auger processes remains within $1 \%$ of the initial value derived for input energies below $5 \mathrm{keV}$, a percentage still within our computation uncertainties. As a consequence, below this input energy, Auger electrons do not play a significant role in the average energy per ion pair.

There is little effect of the atmosphere variation, as shown in Fig. 2 for Earth. We use the neutral atmosphere model

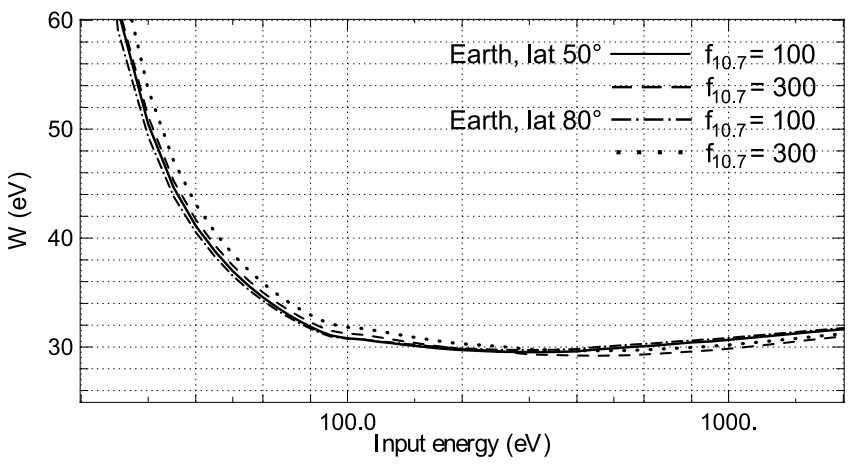

Fig. 2. Latitudinal and solar activity variations of $W_{\text {net }}$ for Earth. Results for latitude $50^{\circ}$ and $80^{\circ}$ are shown for low and high solar activity.

MSIS for different latitudes $\left(50^{\circ}\right.$ and $\left.80^{\circ}\right)$ and two different solar conditions $\left(f_{10.7}=100\right.$ and 300$)$. The latitudinal variations of $W_{\text {net }}$ of around $1 \mathrm{eV}$ remain within the error bars.

\subsection{Single-constituent atmospheres and the bookkeeping problem}

Several authors have published values for single gases, both experimental and theoretical. The underlying motivation is to find the ionisation cost of a planetary atmosphere through a linear combination of the ionisation cost of each separate constituent. We test the validity of this assumption by computing the net ionisation costs for the constituents of Mars' and Earth's atmosphere, using their respective density profiles in the model for the sake of consistency.

The results shown in Table 1 and Fig. 3 for $\mathrm{N}_{2}, \mathrm{O}_{2}$ and $\mathrm{O}$ are in good agreement with previous theoretical studies (Green et al., 1977; Sergienko and Ivanov, 1993) except with that of Fox et al. (2008). Within the error bars, the results for $\mathrm{H}, \mathrm{H}_{2}$ and $\mathrm{He}$ are identical to those of Dalgarno et al. (1999) and Fox et al. (2008). The results for $\mathrm{CO}$ and $\mathrm{CO}_{2}$ disagree by around $5 \mathrm{eV}$ (Green et al., 1977). This is explained by the fact that we have included all known dissociation channels from the work of Itikawa $(2002,2006,2009)$ and Avakyan (1998): for instance $\mathrm{CO}_{2}$ can yield $\mathrm{CO}_{2}^{+}$and $\mathrm{CO}^{+}$but also the fragments $\mathrm{C}^{+}$and $\mathrm{O}^{+}$. If we do not take the latter fragments into account, $W$ values become consistent $(34.0 \mathrm{eV})$ with previous theoretical studies. Thus, this could explain the apparent agreement of previous works with experiments and emphasises the need for a central database for cross sections.

When compared to experimental measurements, our results are in very good agreement for $\mathrm{N}_{2}, \mathrm{O}, \mathrm{CH}_{4}$ and $\mathrm{H}_{2}$. A large discrepancy is seen for $\mathrm{He}$, but none of the theoretical studies including ours manage to reproduce the experimental value. For $\mathrm{CO}_{2}$ and $\mathrm{CO}$, the results of the model are systematically lower than the experimental values by around $5 \mathrm{eV}$. This points out to the bookkeeping problem: including all 


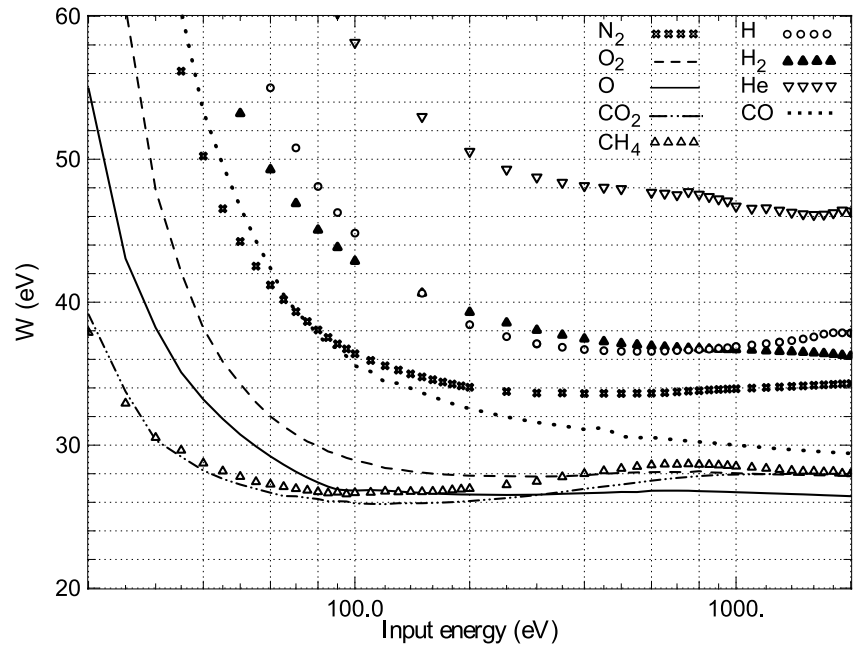

Fig. 3. $W_{\text {net }}$ values for single constituent atmospheres: $\mathrm{N}_{2}, \mathrm{O}_{2}, \mathrm{O}$, $\mathrm{CO}_{2}, \mathrm{CO}, \mathrm{CH}_{4}, \mathrm{H}, \mathrm{H}_{2}$ and $\mathrm{He}$.

documented inelastic collisions is not enough to reproduce experimental values. As shown in Itikawa (2002), uncertainties for recommended $\mathrm{CO}_{2}$ cross sections vary significantly: $10 \%$ in the case of ionisation), $12 \%$ for dissociation producing neutral fragments and up to $30 \%$ for electronic excited states (some ambiguity remaining in the assignment of the states).

To summarise the bookkeeping problem, all $W$ values have been plotted in Fig. 4 from the data of Table 1 for all authors. It is clear from this figure that we have a comprehensive and reliable cross section data set for some species $\left(\mathrm{N}_{2}, \mathrm{O}, \mathrm{CH}_{4}\right.$ and $\left.\mathrm{H}_{2}\right)$, a reasonable estimate for two others $(\mathrm{H}$ and $\mathrm{He}$ ), while for $\mathrm{CO}_{2}, \mathrm{CO}$ and $\mathrm{O}_{2}$ the uncertainties on the cross sections are much too large to yield consistent values. To remove the ambiguity, laboratory measurements should be conducted on electronic excited states of these molecules. A NASA report is being prepared on cross sections and their uncertainties and how they propagate in the computations of aeronomy ionisation and production profiles. This report will also discuss the work needed to improve our database for aeronomic calculations.

Finally, from single species values it is possible to retrieve the $W$ values of the complete atmospheres by way of a statistical weight in the linear combinations of single-constituent $W$. Valentine and Curran (1958) proposed to use the densities or the partial pressure of constituents. We propose a different and simpler empirical method for planetary atmospheres which uses instead the partial column densities of each constituent. Ion productions are indeed a function of the column density, more precisely calculated at the ionisation peak. Hence, to get a good enough approximation of $W$, we perform a linear combination of single constituents with partial column densities for the entire thermosphere.

For Mariner 6 conditions given by MTGCM (Bougher et al., 1999), the partial column densities above $100 \mathrm{~km}$ altitude

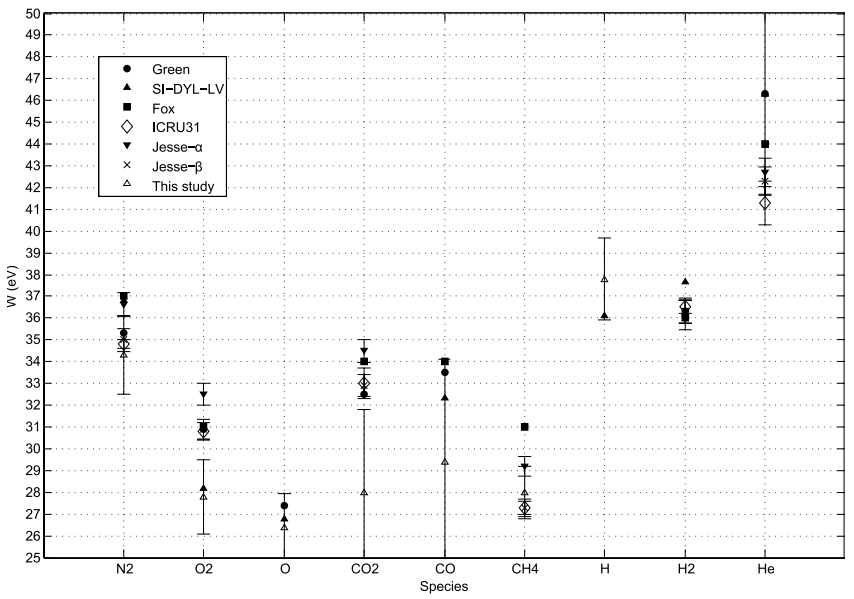

Fig. 4. $W$ values from Table 1 for $\mathrm{N}_{2}, \mathrm{O}_{2}, \mathrm{O}, \mathrm{CO}_{2}, \mathrm{CO}, \mathrm{CH}_{4}$, $\mathrm{H}, \mathrm{H}_{2}$ and $\mathrm{He}$. Error bars are displayed for IRCU data (standard deviation of all experimental records), Jesse and Sadaukis (1957) $(1.5 \%)$ and our study (cross section uncertainties). Discrepancies are seen between experimental and modelling efforts when there is a lack of accurate and complete cross section data set. This is the case for $\mathrm{CO}_{2}, \mathrm{O}_{2}$ and $\mathrm{CO}$ (never measured in laboratory), despite the use in this case of the most up-to-date cross sections available in the literature. Since Mars and Venus are mainly composed of these two species, a specific effort from experimentalists is strongly encouraged.

are $95.5 \% \mathrm{CO}_{2}, 3 \% \mathrm{~N}_{2}, 0.6 \% \mathrm{CO}$ and $0.5 \% \mathrm{O}$. The linear combination of these single constituents yields a reconstituted Mars value $W_{\text {Mars }}^{\mathrm{r}}$ :

$$
\begin{aligned}
W_{\text {Mars }}^{\mathrm{r}} & =0.955 W_{\mathrm{CO}_{2}}+0.030 W_{\mathrm{N}_{2}}+0.006 W_{\mathrm{CO}}+0.005 W_{\mathrm{O}} \\
& =28.1[\mathrm{eV}]
\end{aligned}
$$

which is in good agreement owing to uncertainties with the overall value of $28.4 \mathrm{eV}$ computed in Table 1. At Earth, the column density above $90 \mathrm{~km}$ altitude is $79 \% \mathrm{~N}_{2}, 18 \% \mathrm{O}_{2}$ and $3 \% \mathrm{O}$ yielding a recomposed $W_{\text {net }}$ value of $32.9 \mathrm{eV}$, to be compared with the value of $31.7 \mathrm{eV}$ from Table 1 for the complete Earth atmosphere. Both values lie well within the error bars due to the energy conservation and due to cross sections uncertainties. The same linear combination of the single-constituent energy dependences was also performed in Fig. 5 and compares well with the original calculated full atmosphere $W$ values. The curves lie within $1 \mathrm{eV}$ at energies above $100 \mathrm{eV}$ : for Mars, the agreement is nearly perfect as the atmosphere does not vary significantly in composition with altitude, while at Earth, which atmosphere undergoes large changes above the ionisation peak (lower energies), differences up to a few $\mathrm{eV}$ are seen below $100 \mathrm{eV}$ input energy. 


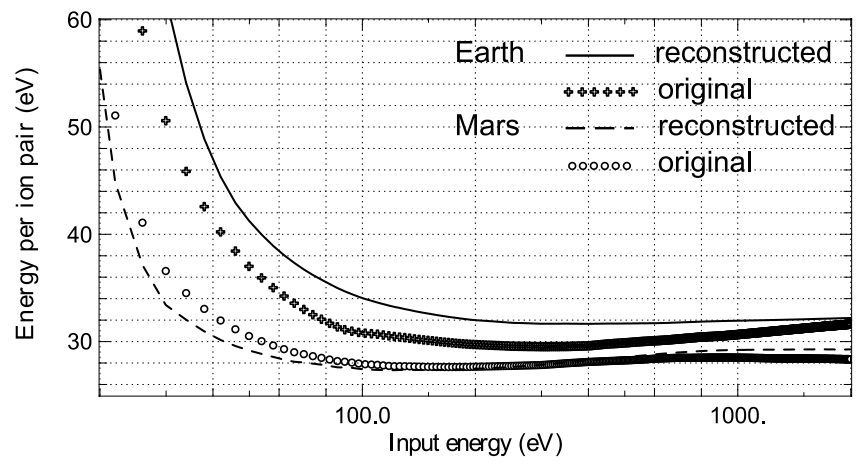

Fig. 5. $W_{\text {net }}$ values from the calculation of the whole atmosphere of Earth and Mars (lines) as compared to the reconstructed atmospheres from a linear combination of the single species $W$ values.

\section{Conclusions}

For the first time, a comprehensive calculation of $W$ values for five major planetary objects in the Solar System has been carried out taking into account the errors due to cross section uncertainties and to numerical approximations. Table 1 summarizes the results of this work, which are in good agreement with previous studies, both experimental and theoretical, for a number of gases of planetology interest including $\mathrm{N}_{2}, \mathrm{O}$, $\mathrm{CH}_{4}$ and $\mathrm{H}_{2}$. This work will be used in a second step to estimate quickly and with reliability the energy deposition of electrons in the upper atmospheres of Mars, Venus, Titan and Jupiter, in view of present and future missions. Following these results, we propose a simple empirical method to retrieve the energy per electron-ion pair for multi-constituent atmospheres by using the partial column density of the thermospheric components instead of partial pressures. We stress the fact that there exists a significant discrepancy between experimental and theoretical records for $\mathrm{CO}_{2}, \mathrm{CO}$ and $\mathrm{O}_{2}$, which stems from the large uncertainties in the inelastic cross sections available in the literature and also the non-inclusion of the preceding models of all dissociation channels. Improvements on the measurement of these cross sections and also of Auger processes in $\mathrm{CO}_{2}$ and $\mathrm{CO}$ are strongly encouraged.

Acknowledgements. We thank the EISCAT staff in Troms $\varnothing$ and R. Jacobsen for their help. The research leading to these results has received funding from the European Commission's Seventh Framework Programme (FP7/2007-2013) under the grant agreement no. 218816 (SOTERIA project, www.soteria-space.eu) and under the grant agreement no. 228319 (Europlanet research infrastructure http://www.europlanet-ri.eu/. This research was also carried out in the frame of the European COST ES0803 project. The work of G.G. was supported by an appointment to the NASA Postdoctoral Program at NASA Langley Research Center, administered by Oak Ridge Associated University through a contract with NASA. The simulations were made using the CIGRI system on the CIMENT platform (Grenoble UJF, France). We thank B. Bzeznik (IMAG, France) for his useful advice. We also thank the two refer- ees for their insightful comments. C.S.W is indebted to M. S. Wedlund (LATMOS, France) for her comments and rereading of the present manuscript.

Topical Editor K. Kauristie thanks S. Avakyan and another anonymous referee for their help in evaluating this paper.

\section{References}

Avakyan, S. V.: Auger electrons in auroral ionosphere, Geomagn. Aeronom., 23(2), 324-326, 1983.

Avakyan, S. V. (Ed.): Collision processes and excitation of UV emission from planetary atmospheric gases : a handbook of cross sections, Amsterdam, The Netherlands: Gordon and Breach Science Publishers, 1998.

Avakyan, S. V. and Kudryashev, G. S.: Features of the effective ionization cross section method, Geomag. Aeron., 28, 452-456, 1988 (in Russian).

Bagge, E.: Über die Berechnung der mittleren Ionisierungsenergie der Gase, Annal. Phys., 422, 72-90, doi:10.1002/andp.19374220105, 1937.

Basu, B., Jasperse, J. R., Strickland, D. J., and Daniell Jr., R. E.: Transport-theoretic model for the electron-protonhydrogen atom aurora. 1: Theory, J. Geophys. Res., 98, 21517, doi:10.1029/93JA01646, 1993.

Bethe, H.: Zur Theorie des Durchgangs schneller Korpuskularstrahlen durch Materie, Annal. Phys., 397, 325-400, doi:10.1002/andp.19303970303, 1930.

Bevington, P. R. and Robinson, D. K.: Data reduction and error analysis for the physical sciences, 3rd ed., Boston, MA: McGraw-Hill, ISBN 0-07-247227-8, 2003.

Bougher, S. W., Engel, S., Roble, R. G., and Foster, B.: Comparative terrestrial planet thermospheres 2. Solar cycle variation of global structure and winds at equinox, J. Geophys. Res., 104, 16591-16611, doi:10.1029/1998JE001019, 1999.

Bretagne, J., Delouya, G., Godart, J., and Puech, V.: Highenergy electron distribution in an electron-beam-generated argon plasma, J. Phys. D: Appl. Phys., 14, 1225-1239, doi:10.1088/0022-3727/14/7/011, 1981.

Carrasco, C., Dutuit, O., Thissen, R., Banaszkiewicz, M., and Pernot, P.: Uncertainty analysis of bimolecular reactions in Titan ionosphere chemistry model, Plan. Space Sci., 55, 141-157, doi:10.1016/j.pss.2006.06.004, 2007.

Chamberlain, J. W.: Physics of the aurora and airglow, International Geophysics Series, vol. 2, New York: Academic Press, ISBN 0875908578, 1961.

Cui, J., Galand, M., Yelle, R. V., Vuitton, V., Wahlund, J., Lavvas, P. P., Müller-Wodarg, I. C. F., Cravens, T. E., Kasprzak, W. T., and Waite, J. H.: Diurnal variations of Titan's ionosphere, J. Geophys. Res., 114, 6310, doi:10.1029/2009JA014228, 2009.

Dalgarno, A. and Griffing, G. W.: Energy per Ion Pair for Electron and Proton Beams in Atomic Hydrogen, Roy. Soc. Lond. Proc. Ser. A, 248, 415-428, 1958.

Dalgarno, A., Yan, M., and Liu, W.: Electron Energy Deposition in a Gas Mixture of Atomic and Molecular Hydrogen and Helium, Astrophys. J. Supp. S., 125, 237-256, doi:10.1086/313267, 1999.

Edgar, B. C., Miles, W. T., and Green, A. E. S.: Energy deposition of protons in molecular nitrogen and applications to 
proton auroral phenomena., J. Geophys. Res., 78, 6595-6606, doi:10.1029/JA078i028p06595, 1973.

Fano, U.: On the Theory of Ionization Yield of Radiations in Different Substances, Phys. Rev., 70, 44-52, doi:10.1103/PhysRev.70.44, 1946.

Fox, J. L., Galand, M. I., and Johnson, R. E.: Energy Deposition in Planetary Atmospheres by Charged Particles and Solar Photons, Space Sci. Rev., 139, 3-62, doi:10.1007/s11214-008-94037, 2008

Frémont, F., Hajaji, A., and Chesnel, J.: $\mathrm{K}$-shell and total ionization cross sections following electron-molecule collisions: An empirical scaling law, Phys. Rev. A, 74, 052707, doi:10.1103/PhysRevA.74.052707, 2006

Glupe, G. and Mehlhorn, W.: A new method for measuring electron impact ionization cross sections of inner shells, Phys. Lett. A, 25, 274-275, doi:10.1016/0375-9601(67)90901-2, 1967.

Glupe, G. and Mehlhorn, W.: Absolute Electron Impact Ionization Cross Sections of N, O and Ne, J. Phys. Colloques, 32, C4-40C4-4, doi:10.1051/jphyscol:1971408, 1971.

Green, A. E. S., Jackman, C. H., and Garvey, R. H.: Electron impact on atmospheric gases. II - Yield spectra, J. Geophys. Res., 82, 5104-5111, doi:10.1029/JA082i032p05104, 1977.

Grodent, D. and Gérard, J.-C.: A self-consistent model of the Jovian auroral thermal structure, J. Geophys. Res., 106, 12933-12952, doi:10.1029/2000JA900129, 2001

Gronoff, G., Lilensten, J., Simon, C., Witasse, O., Thissen, R., Dutuit, O., and Alcaraz, C.: Modelling dications in the diurnal ionosphere of Venus, Astron. \& Astrophys., 465, 641-645, doi:10.1051/0004-6361:20065991, 2007.

Gronoff, G., Lilensten, J., Simon, C., Barthélemy, M., Leblanc, F., and Dutuit, O.: Modelling the Venusian airglow, Astron. Astrophys., 482, 1015-1029, doi:10.1051/0004-6361:20077503, 2008

Gronoff, G., Lilensten, J., Desorgher, L., and Flückiger, E.: Ionization processes in the atmosphere of Titan. I. Ionization in the whole atmosphere, Astron. Astrophys., 506, 955-964, doi:10.1051/0004-6361/200912371, 2009.

Hedin, A. E.: Extension of the MSIS thermosphere model into the middle and lower atmosphere, J. Geophys. Res., 96, 1159-1172, doi:10.1029/90JA02125, 1991

Hedin, A. E., Niemann, H. B., Kasprzak, W. T., and Seiff, A.: Global empirical model of the Venus thermosphere, J. Geophys. Res., 88, 73-83, doi:10.1029/JA088iA01p00073, 1983.

ICRU Report: Average energy required to produce an ion pair, Report No. 31, International Commission on Radiation Units and Measurements, Washington, D.C.: ICRU Publications, ISBN 0913394-25-4, 1979, reprinted 1993.

Inokuti, M.: Ionization yields in gases under electron irradiation, Rad. Res., 64, 6-22, 1975.

Itikawa, Y.: Cross Sections for Electron Collisions With Carbon Dioxide, J. Phys. Chem. Ref. Data, 31, 749, doi:10.1063/1.1481879, 2002.

Itikawa, Y.: Cross Sections for Electron Collisions with Nitrogen Molecules, J. Phys. Chem. Ref. Data, 35, 31, doi:10.1063/1.1937426, 2006.

Itikawa, Y.: Cross Sections for Electron Collisions with Oxygen Molecules, J. Phys. Chem. Ref. Data, 38, 1-20, doi:10.1063/1.3025886, 2009.

Jesse, W. P. and Sadaukis, J.: Absolute Energy to Produce an Ion
Pair by Beta Particles from S $\mathrm{S}^{35}$, Phys. Rev., 107, 766-771, 1957.

Johnson, P. V., Kanik, I., McConkey, J. W., and Tayal, S. S.: Collisions of electrons with atomic oxygen: current status, Can. J. Phys., 83, 589-616, doi:10.1139/p05-034, 2005.

Khare, S. P.: Mean energy expended per ion pair by electrons in atmospheric gases, J. Phys. B At. Mol. Phys., 3, 971-975, 1970.

Khare, S. P.: Corrigendum: Mean energy expended per ion pair by electrons in atomospheric gases, J. Phys. B At. Mol. Phys., 4, 886, 1971.

Khare, S. P. and Kumar Jr., A.: Mean energy expended per ion pair by electrons in molecular nitrogen, J. Phys. B: At. Mol. Phys., 10, 2239-2251, doi:10.1088/0022-3700/10/11/024, 1977.

Khare, S. P. and Kumar Jr., A.: Mean energy expended per ion pair by electrons in molecular oxygen, J. Phys. B: At. Mol. Phys., 11, 2403-2410, doi:10.1088/0022-3700/11/13/024, 1978.

Kozelov, B. V. and Ivanov, V. E.: Effective energy loss per electron-ion pair in proton aurora, Ann. Geophys., 12, 10711075, doi:10.1007/s00585-994-1071-7, 1994.

Lehmann, J. F. and Osgood, T. H.: The Total Ionisation due to the Absorption in Air of Slow Cathode Rays, Roy. Soc. Lond. Proc. Ser. A, 115, 609-624, 1927.

Lilensten, J., Fontaine, D., Kofman, W., Lathuillere, C., and Eliasson, L.: Electron energy budget in the high-latitude ionosphere during Viking/EISCAT coordinated measurements, J. Geophys. Res., 95, 6081-6092, doi:10.1029/JA095iA05p06081, 1990.

Lilensten, J., Simon, C., Witasse, O., Dutuit, O., Thissen, R., and Alcaraz, C.: A fast computation of the diurnal secondary ion production in the ionosphere of Titan, Icarus, 174, 285-288, doi:10.1016/j.icarus.2004.12.002, 2005.

Liu, W. and Victor, G. A.: Electron energy deposition in carbon monoxide gas, Astrophys. J., 435, 909-919, doi:10.1086/174872, 1994.

Lummerzheim, D. and Lilensten, J.: Electron transport and energy degradation in the ionosphere: evaluation of the numerical solution, comparison with laboratory experiments and auroral observations, Ann. Geophys., 12, 1039-1051, doi:10.1007/s00585994-1039-7, 1994.

Ménager, H., Barthélemy, M., and Lilensten, J.: H Lyman $\alpha$ line in Jovian aurorae: electron transport and radiative transfer coupled modelling, Astron. Astrophys., 509, A260000, doi:10.1051/0004-6361/200912952, 2010.

Müller-Wodarg, I. C. F., Yelle, R. V., Mendillo, M., Young, L. A., and Aylward, A. D.: The thermosphere of Titan simulated by a global three-dimensional time-dependent model, J. Geophys. Res., 105, 20833-20856, doi:10.1029/2000JA000053, 2000.

Opal, C. B., Peterson, W. K., and Beaty, E. C.: Measurements of Secondary-Electron Spectra Produced by Electron Impact Ionization of a Number of Simple Gases, J. Chem. Phys., 55, 41004106, 1971.

Platzman, R. L.: Total ionization in gases by high-energy particles: an appraisal of our understanding, Int. J. Appl. Radiat. Isot., 10, 116-127, 1961.

Porter, H. S. and Jump, F. W.: Analytic total and angular elastic electron impact cross sections for planetary atmospheres, Tech Rep. CSC/TM-6017, Goddard Space Flight Center, Greenbelt, Md., 1978.

Porter, H. S., Varosi, F., and Mayr, H. G.: Iterative solution of the multistream electron transport equation. I - Comparison with laboratory beam injection experiments, J. Geophys. Res. 92, 
5933-5959, 1987.

Rees, M. H.: Auroral ionization and excitation by incident energetic electrons, Planet. Space Sci., 11, 1209, doi:10.1016/00320633(63)90252-6, 1963.

Rees, M. H.: Physics and chemistry of the upper atmosphere, Cambridge, UK: Cambridge University Press, ISBN 0521368480, 1989.

Samson, J. A. R. and Haddad, G. N.: Average Energy Loss Per Ion Pair Formation By Photon and Electron Impact, in: Physics of Electronic and Atomic Collisions: ICPEAC IX, edited by: Barnett, C. F., pp. 1133, 1975.

Semeter, J. and Kamalabadi, F.: Determination of primary electron spectra from incoherent scatter radar measurements of the auroral E region, Radio Sci., 40, RS2006, doi:10.1029/2004RS003042, 2005.

Sergienko, T. I. and Ivanov, V. E.: A new approach to calculate the excitation of atmospheric gases by auroral electrons, Ann. Geophys., 11, 717-727, 1993.

Simon, C., Lilensten, J., Moen, J., Holmes, J. M., Ogawa, Y., Oksavik, K., and Denig, W. F.: TRANS4: a new coupled electron/proton transport code - comparison to observations above Svalbard using ESR, DMSP and optical measurements, Ann. Geophys., 25, 661-673, doi:10.5194/angeo-25-661-2007, 2007.
Simon, C., Witasse, O., Leblanc, F., Gronoff, G., and Bertaux, J.: Dayglow on Mars: Kinetic modelling with SPICAM UV limb data, Planet. Space Sci., 57, 1008-1021, doi:10.1016/j.pss.2008.08.012, 2009.

Slinker, S. P., Taylor, R. D., and Ali, A. W.: Electron energy deposition in atomic oxygen, J. Appl. Phys., 63, 1-10, doi:10.1063/1.340491, 1988.

Slinker, S. P., Ali, A. W., and Taylor, R. D.: High-energy electron beam deposition and plasma velocity distribution in partially ionized $\mathrm{N}_{2}$, J. Appl. Phys., 67, 679-690, doi:10.1063/1.345772, 1990.

Stolarski, R. S. and Green, A. E. S.: Calculations of Auroral Intensities from Electron Impact, J. Geophys. Res., 72, 3967, doi:10.1029/JZ072i015p03967, 1967.

Strickland, D. J. and Ali, A. W.: A code for the secondary electron energy distribution in air and some applications, Tech. rep., 1982.

Strickland, D. J., Daniell, Jr., R. E., Jasperse, J. R., and Basu, B.: Transport-theoretic model for the electron-proton-hydrogen atom aurora. 2: Model results, J. Geophys. Res., 98, 21533, doi:10.1029/93JA01645, 1993.

Valentine, J. M. and Curran, S. C.: Average energy expenditure per ion pair in gases and gas mixtures, Rep. Prog. Phys., 21, 1-29, doi:10.1088/0034-4885/21/1/301, 1958. 